\title{
Article
}

\section{Qualitative Assessment of Social Vulnerability to Flood Hazards in Romania}

\author{
Ibolya Török
}

Faculty of Geography, Babeș-Bolyai University of Cluj-Napoca, Clinicilor Street 5-7, 400006 Cluj-Napoca, Romania; ibolya.torok@ubbcluj.ro; Tel.: +40-744-694-161

Received: 4 September 2018; Accepted: 17 October 2018; Published: 19 October 2018

\begin{abstract}
This paper investigates local-scale social vulnerability to flood hazards in Romania, aiming to identify the most vulnerable social and demographic groups across a wide range of geographical locations by considering three dimensions: demographic, socioeconomic, and the built environment. The purpose of the paper is threefold: first, it strives to improve the Social Vulnerability model $\left(\mathrm{SoVI}^{\circledR}\right)$ by applying a different weighting method adapted to the Romanian context, taking into consideration the municipalities exposed to flood movements. Second, it aims to develop an assessment model for the most vulnerable communities by measuring the heterogeneity according to local indicators related to disaster risks. Third, it aims to facilitate emergency managers to identify community sub-groups that are more susceptible to loss and to increase the resilience of local communities. To perform local-level vulnerability mapping, 28 variables were selected and three aggregated indexes were constructed with the help of the ArcGIS software. Moreover, a model of Geographically Weighted Regression (GWR) between communities directly affected by floods and localities with high- and very high values of the Local Social Vulnerability Index (LoSoVI) was used to explore the spatial relationship among them and to compare the appropriateness of Ordinary Least Square (OLS) and GWR for such modelling. The established GWR model has revealed that the negative effects of flood hazards are often associated with communities with a high degree of social vulnerability. Thus, the analysis is able to provide a more comprehensive picture on communities in desperate need of financial resources in order to have the ability to diminish the negative impacts of flood hazards and to provide a more sustainable society.
\end{abstract}

Keywords: social vulnerability; flood hazards; LoSoVI model; geographically weighted regression; Romania

\section{Introduction}

Over the last two decades, the importance of analysing social vulnerability has gained major importance, especially in terms of elaborating different methodologies for quantifying the rate of vulnerability, delimiting territories most exposed to risks as well as elaborating effective development strategies. Quantifying the social dimension of vulnerability allows the identification of the most vulnerable regions along with key factors which, once addressed, could increase the resilience of local communities. By analysing a broad set of studies on topics including methodological development [1-3], specific hazard research (climate, floods) [2,4], scale difference analysis (local, international comparison) [1,2], temporal and spatial changes [5], or uncertainty and sensitivity analysis [6], we can see that social vulnerability analysis has come a long way in the last decade. However, due to its multidimensionality, neither a common definition nor a universally accepted measurement has been unanimously accepted so far. Social vulnerability is used, defined, and conceptualised in many different ways [7] and is often linked to associated concepts such as resilience, risk, exposure, sensitivity, and coping capacity [8]. In this article we first present the 
concepts and approaches related to social vulnerability in a critical way, debating afterwards on the issue of developing methods for measuring social vulnerability as well as the advantages and weaknesses of the most frequently used variables.

The evolution of research on vulnerability has been considerably influenced by two distinct approaches: namely, the 'human ecologist school' or 'behavioural paradigm' and the 'structural paradigm'.

The focus of the behavioural paradigm is the human adaptation to natural hazards. Adaptation can be understood as purposeful actions for disaster mitigation, the behavioural paradigm being thus also viewed as a hazard-based approach [9-11]. The structural paradigm-also called a disaster-based approach-focuses on people's individual socio-economic and demographic characteristics within the specific social, economic, cultural, and political context they live in, emphasizing a range of variables determining vulnerability. The structuralism perspective has also led to important theoretical advancements in the field, resulting in the development of various comprehensive models.

The 'Pressure and Release Model' (PAR) reveals the complex interactions between social processes that create vulnerability and the hazards themselves. Within the model, 'pressure' can be understood as an increasing level of vulnerability and exposure to hazards, while the 'release' aspect encompasses all actions taken to reduce the potential negative impact of a disaster. Although explicitly highlighting vulnerability, the PAR model has been strongly criticized as it does not take into account the role of proximity to the source of the threat and it does not address the physical aspects of the interactions between the social- and natural systems [12,13]. The model provides little detail on the hazards' causal sequence and downplays feedback beyond the system of analysis included in the integrative Risk-Hazard models [14]. Thus, it represents a specific tool for explaining vulnerability within descriptive analyses, rather than for empirical testing.

An important conceptual development has emerged along with the elaboration of the hazard-of-place approach to vulnerability, which combines the risk/hazard and political ecology perspectives. The model is based on the assumption that people living in a certain area will have an unequal vulnerability to a potential natural hazard due to their social, economic, and political statuses [15]. In the model, the geographic context and social structure are linked together, having a strong influence on each other. Thus, the interactions between social vulnerability and biophysical vulnerability create place vulnerability, which is then linked to risk and mitigation elements. The most important deficiencies of this model are its weak capability to explain the root causes of social vulnerability, as well as the inability to include the larger context in which social vulnerability exists [12]. However, this approach can be considered a novel contribution with regard to the introduction of GIS technologies not only in risk, hazard, and vulnerability mapping, but also in emergency planning.

Following the internal-external model, which relies on the double structure of vulnerability (exposure/coping), Turner et al. [13] proposed a vulnerability/sustainability framework in order to provide a comprehensive analysis on the complexity and interactions involved in vulnerability analyses, highlighting the factors and linkages that affect the intertwined human and environmental systems exposed to hazards. Since vulnerability is strongly influenced by global processes, the conceptual model stresses the importance of analysing the elements of local vulnerability within the wider context, explicitly considering space, time, and scale. This framework is thus able to show how the interactions of social and environmental forces can result in an increased vulnerability in the event of sudden changes. However, the approach could not escape criticism as it lacks clear differentiation between exposure and sensitivity, making it difficult to identify where vulnerability begins and where it ends [12].

The concept of vulnerability has continuously evolved by including susceptibility, exposure, the capacity to cope and adapt, and by incorporating different thematic areas such as physical, social, economic, environmental and institutional vulnerability [16]. Along with the extensive debate on the conceptualisation of social vulnerability, there are also debates on the issue of developing methods for measuring it. The difficulties have mainly been related to two specific aspects: the availability of databases at different territorial levels and the development of the most appropriate methodology 
which considers all factors of interest, providing necessary information upon which political decisions can be based. Even though there is still no universally agreed-upon set of indicators, methodology or uniquely developed indices for measuring social vulnerability, a series of successful attempts have been published on the topic in recent years. One of the most important pioneering works belongs to Cutter et al. [1] who-by examining social vulnerability in US states-have developed the SoVI ${ }^{\circledR}$ index. This method has largely been accepted due to its continuous evolution $[4,17-20]$, pertinence, and adaptability. The only limitation of the method is that it attributes equal weights to all factors influencing social vulnerability, although there are always certain processes-depending on the analysed region - which can have a stronger impact on shaping social vulnerability. In order to avoid this limitation, most of the research results which have seen the light of day in the last years have focused either on applying different weighting methods [21,22] or on developing completely new methodologies [23,24].

When it comes to assessing social vulnerability, the most frequently used associations of the term are with social processes, economic systems, and relations of power, using variables such as class, ethnicity, gender, age, disability, and health status [25]. However, vulnerability is also linked to the lack of access to resources, building stock, and age, type, and density of infrastructure and lifelines [1]. The approach of measuring social vulnerability through the use of such variables has certain advantages, but it also has weak points [26]. First, by taking into account the demographic characteristics of a society, some authors have argued that women and the elderly are among the most vulnerable, yet information about flood-caused deaths reveals that young and middle-aged men are also vulnerable due to a more risk-taking behaviour [27-29]. Besides this, not all elderly people are equally vulnerable throughout the entire disaster period [26] as old age itself is relative and depends on several factors (illness, fitness). It has also been proven that gender alone is not an explaining factor of vulnerability, as women's living conditions are greatly influenced by socio-economic status, household structures, and geographic location [30]. Education, on the other hand, is a double-faceted variable of social vulnerability. Although well-educated people usually have a higher income and better-positioned properties, the occurrence of natural disasters can potentially result in higher damages. Albeit, the coping capacity of wealthier households is much higher than that of poorer households (having a home insurance can significantly reduce the burden of damages).

The political, environmental and socio-economic context that it is being applied to should be considered.

The most important strength of assessing social vulnerability by using an indicator- and place-based approach is represented by its practical applicability. Thus, once embedded into the wider/national context, it can assess the communities' preparedness for diminishing the negative effects of natural hazards, representing at the same time a valuable input for policy-makers and disaster planners.

In spite of the fact that over the last decades a series of studies have dealt with the issue of social vulnerability in Romania, there is still a strong need to improve the methodology in order to increase its reliability in the context of disaster risk reduction. The most relevant research papers belong to Stângă and Grozavu [31], Armaş and Gavriş [32], Bănică and Muntele [33], Constantin et al. [34], although it is worth mentioning that these studies focus mainly on smaller spatial scales, applying comparative case studies for various parts of regions or for different territorial administrative units (i.e., the Municipality of Bucharest, rural mining settlements in the Apuseni Mountains, Iaşi and Bacău cities and metropolitan areas). Török [35] has applied a modified version of the original SoVI in the Romanian context, proving the workability of the algorithm in a different context of development, using place-specific indicators.

The first and most important result of the study, following the hazard-of-place approach, is the elaboration of place-based indicators along with a specific weighting scheme for measuring local social vulnerability in regions where floods and flood-related hazards are important causes of disasters. The indicators can be well incorporated into other vulnerability models, being relevant and most 
useful in the vulnerability assessment of other regions characterized by demographic ageing and low to average levels of income as well. Nevertheless, different case studies across countries and regions along with methodological advancements can further enhance the international applicability of the model and the comparison methods of social vulnerability across different areas. Second, analysing social vulnerability across different territories gives emergency managers a meaningful and practical overview of the state of the art, offering the possibility of a much more precise planning and management for emergency situations. The present study found that social status is the most important indicator of vulnerability to disasters in Romanian settlements. Therefore, emergency managers should concentrate their efforts on offering support, advice, and counselling to those specific segments of the population which lack access to basic information on emergency situations and information on emergency management. Third, the present study also reveals the importance of integrating social vulnerability and disaster risk mitigation with the concept of sustainable development. How people live and how society develops has a direct effect on the overall value of potential losses due to disasters. Therefore, the specific results of the study can serve as a starting point for central and local public authorities for drafting and including measures for mitigating existing disaster risks in future development plans and policies, while also striving to develop sustainable communities.

Therefore, the main purpose of the paper is to quantify social vulnerability to natural hazards in Romanian settlements by using a large set of indicators, by applying a new weighting method and by elaborating the Local Social Vulnerability Index (LoSoVI). The results will be used to explore and analyse the spatial relationship between flood hazards and communities with a high degree of social vulnerability, using geographically weighted regression, comparing the results of OLS and GWR modelling at the same time.

\section{Materials and Methods}

\subsection{The Study Area}

With 19.9 million inhabitants according to the latest available census, Romania is one of the largest countries in the EU.

Regarding the territorial-administrative units, the country is organized as follows: counties, cities, towns, communes, and villages. To these, we can add the eight development regions which gained importance after the EU accession, mainly in relation to aspects related to regional development projects and EU funding, although they have neither an administrative status nor a legislative or executive council or government. The names and abbreviations of the counties are listed in the Abbreviations Section.

Hydrographically speaking, Romania is divided into 11 hydrographic units (Figure 1).

If we consider the presence of natural hazards, it can be stated that Romania is a country with a high seismic activity and frequent occurrences of extreme phenomena. Romania is also known as one of the most flood-prone countries in Europe with major economic and social consequences, floods usually taking place along the course of internal rivers as well as the Danube [36], with a higher incidence in the north-eastern and north-western parts of the country (Figure 1). 


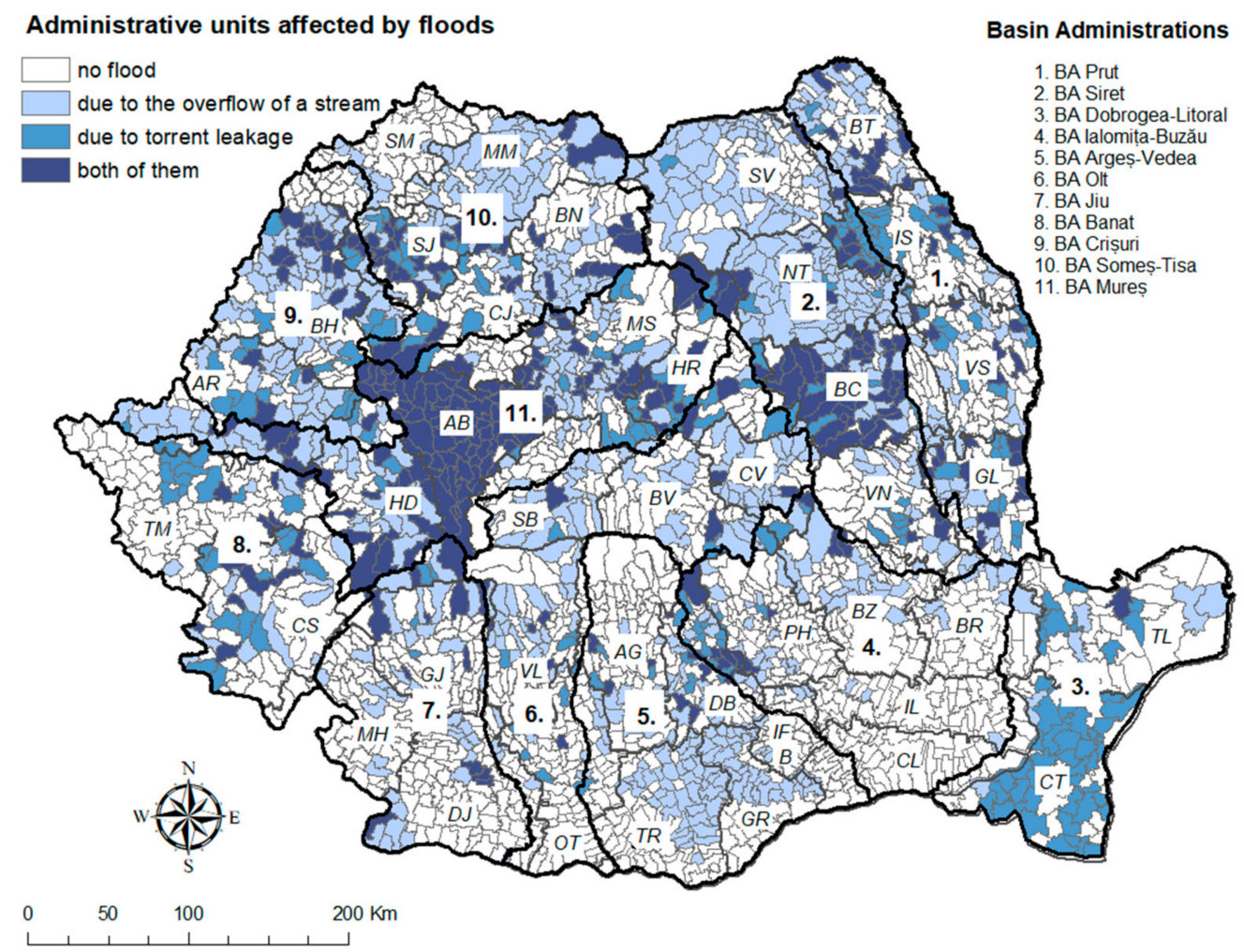

Figure 1. The administrative units affected by floods.

\subsection{Selection of Variables}

While vulnerability is a scale-dependent variable where global, regional, and national scale assessments allow for comparisons across nations, the local scale is more important in disaster risk reduction planning [37]. Having this in mind, the analysis of social vulnerability was based on the lowest administrative level which in our case is represented by 3181 study units (including 2861 communes and 320 cities). Statistical data obtained from the National Institute of Statistics, including the 2011 Census, as well as the Tempo Online web database, enabled us to use a large set of variables [38].

The most challenging task in constructing a social vulnerability index is the choice of the major indicators, as the selection depends on both the quality of available variables as well as on the subjectivity of decisions [39]. Therefore, the selected indicators used in this study greatly differ from the original SoVI ${ }^{\circledR}$ model, as the approach was adapted to the Romanian context, taking into account their relevance to the country's situation and reality. The use of different indicators could also be observed in Norway [17], China [18], Portugal [40], Brazil [41], India [42], Vietnam [43], etc. When choosing the indicators, the author has also considered the context and framework drawn up by the main purpose of the study, namely to identify the most vulnerable areas and to reveal the spatial relationship which exists between the flooding and vulnerable communities. After a deep review of the related literature, a total of 27 variables were selected, representing the most relevant factors which have already shown to influence social vulnerability to flood hazards. The variables were then grouped into three major categories, in a completely different manner compared to previous researches [35], comprising also data related to the built infrastructure. Table 1 gives a list of the 27 variables used to develop the social vulnerability index for the settlements, together with their descriptive statistics based on 3181 cases. 
Table 1. Descriptive statistics of variables considered for social vulnerability assessment.

\begin{tabular}{ccccc}
\hline Variables & Mean & SD & Min & Max \\
\hline Share of households with access to piped water & 39.58 & 25.59 & 0.06 & 99.07 \\
Share of households with access to a sewage network & 37.34 & 24.90 & 0.06 & 99.00 \\
Share of households with a central heating system & 11.72 & 16.82 & 0.06 & 96.36 \\
Share of households with a kitchen area & 73.76 & 17.28 & 1.38 & 99.67 \\
Share of households with a fixed bath & 33.14 & 23.54 & 0.06 & 99.84 \\
Average number of people per household & 16.50 & 4.64 & 2.65 & 92.40 \\
Number of housing units per square kilometre & 2.47 & 0.54 & 0.22 & 8.37 \\
Number of houses constructed from wood & 12.53 & 16.28 & 0.00 & 94.60 \\
Number of houses with a reinforced structure & 0.57 & 1.06 & 0.00 & 12.22 \\
Population density & 103.47 & 303.92 & 1.35 & 8144.87 \\
Share of population aged 65 years and above & 25.16 & 7.59 & 2.12 & 77.01 \\
Demographic dependency ratio & 1694.35 & 865.85 & 123.25 & 8676.47 \\
Share of widows within female population & 11.34 & 3.55 & 1.52 & 45.56 \\
Share of the Roma population & 1.48 & 4.46 & 0.00 & 81.11 \\
Number of births per 1000 persons & 9.11 & 4.29 & 0.00 & 67.43 \\
Share of the population under 5 years old & 16.29 & 4.12 & 1.30 & 59.22 \\
Net international migration rate & 1.11 & 9.03 & -74.70 & 74.20 \\
Share of women from the total population & 46.99 & 5.13 & 9.79 & 94.33 \\
Percent employed in services & 26.90 & 14.09 & 5.28 & 88.25 \\
Share of population with university education & 5.06 & 4.37 & 0.00 & 44.61 \\
Access to major public road networks & 1.92 & 1.06 & 0.00 & 5.00 \\
Access to railway transportation & 1.33 & 1.83 & 0.00 & 5.00 \\
Illiteracy rate & 2.12 & 2.10 & 0.03 & 30.46 \\
Per capita income & 568.85 & 537.81 & 10.57 & 9740.21 \\
Entrepreneurial activity rate & 24.71 & 4.27 & 0.00 & 47.20 \\
Employment rate & 61.6 & 23.62 & 1.27 & 78.2 \\
Tax collection rate at the local budget level & 0.36 & 0.26 & 0.08 & 5.00 \\
\hline Notes SD Standar Deviaton Max Maxim & & & &
\end{tabular}

Notes: $\mathrm{SD}=$ Standard Deviation. Max = Maximum value. Min = Minimum value. $N=3181$.

\subsection{Methods}

Following the hazard-of-place model approach [15], the methodological framework for assessing the social vulnerability index to flood hazards has included the following steps: first, the socio-economic and built infrastructure related variables were standardized, producing variables with a zero mean and a standard deviation of one. Then, a Principal Component Analysis (PCA) was used to create vulnerability indices from the standardized variables. The PCA technique compresses an original set of variables into a smaller set by identifying patterns in high-dimensional data and revealing the principal factors which best describe variations in the data by finding and clustering variables that measure the same theme [44]. While constructing the PCA analysis we have also paid attention to the collinearity analysis and the elimination of redundant data. To check the robustness of the model, two statistical tests-the Kaiser-Meyer-Olkin (KMO) for sampling adequacy and Bartlett's Test of Sphericity-were used. KMO values above 0.6 indicate an acceptable level, while values above 0.8 denote a good compatibility level of variables [45]. Bartlett's test of Sphericity verifies whether the correlation matrix is an Identity Matrix, where all the diagonals are 1 and the off-diagonals are 0 . If this is the case, none of the variables in the respective matrix are correlated. Finally, Varimax rotation with Kaiser Normalization was used to make the data orthogonal by increasing the interpretability of the factors. This technique minimizes the number of variables which have high loading on a single factor and clarifies the interpretation of the factors. We reduce the number of dimensions by working with only those provisional indexes whose eigenvalues from the PCA are larger than 1.0, provided that we could clearly identify each component. Therefore, components with absolute loading values below 0.5 have been left out. Following the factor rotation stage, a directional adjustment process is applied to the entire factor in order to ensure that the individual component variables all act in the same direction, increasing or decreasing the vulnerability. Thus components enhancing vulnerability 
were considered positive, while those which reduced it were considered negative. As a consequence, we assign a positive score when the resulting factor increases the total vulnerability, and a negative score when it decreases it. In order to get a more comprehensive picture, we have applied the PCA analysis separately to the built-in, demographic, as well as to the socio-economic dimensions. Figure 2 shows the flowchart guiding the analytical process.

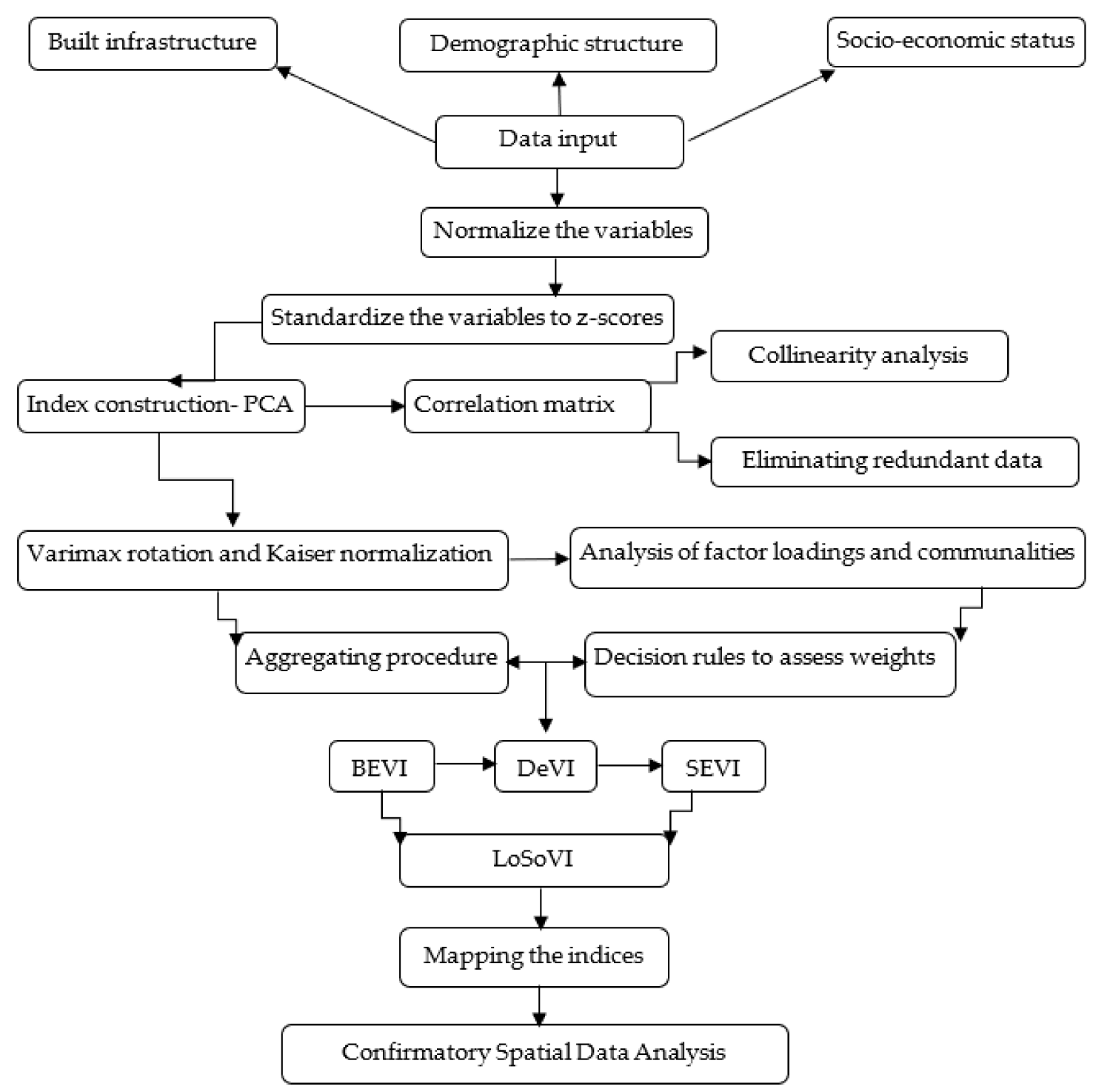

Figure 2. The framework of the analysis.

The most important/methodological development is represented by the elaboration of an adequate weighting scheme, as not all factors contribute to the overall vulnerability assessment in the same proportion. Since there is no commonly accepted framework defining such a weighting method, several authors used different approaches to assign weights to the specific indices. A brief overview of these can be found in Table 2 . 
Table 2. The relevant studies on measuring social vulnerability.

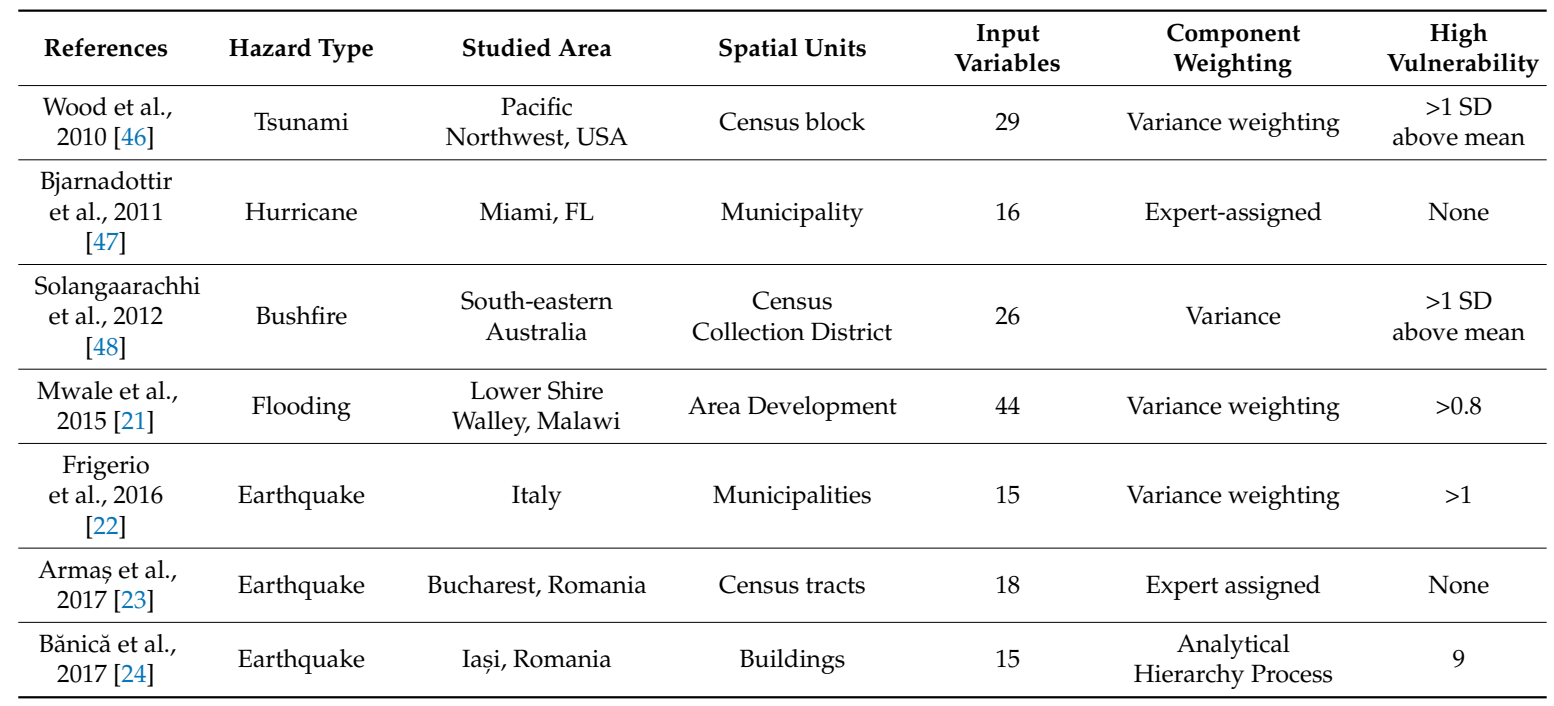

As we can observe from the explanation of the cumulative variance provided by the PCA analysis (Table 3), each factor score was assigned according to the number of variables related to each component (e.g., for $F_{1}, \mathrm{v}=5$; for $F_{2}, \mathrm{v}=2$ ) and multiplied by the weight assigned for each specific factor. The weight was calculated using the total variance explained and the percentage variance explained for each component.

$$
W_{i}=\frac{\text { Explainable variance }}{\text { Total percent varianced explained }} * 100
$$

In the first step, we have applied the PCA analysis separately for the built environment resulting in the Built Environment Vulnerability Index (BEVI), separately for the demographic structure forming the Demographic Vulnerability Index (DeVI) as well as for the socio-economic dimension (SEVI), using the following equation.

$$
\text { LoSoVI }=\sum_{i=1}^{n} B E V I+\operatorname{DeVI}+\operatorname{SEVI}\left(\frac{F_{i}}{v_{i}} * w_{i}\right),
$$

where, $n=$ the number of territorial units, $F=$ the resulting number of factors, $v=$ the number of variables included in each factor, $w=$ the assigned weight for each factor. Therefore, in the last step, the LoSoVI for all Romanian settlements was calculated with the following equation:

$$
\begin{aligned}
\text { LoSoVI }=\sum_{i=1}^{n} B E V I & -\left(\frac{F_{1}}{5} * 58.3\right)+\left(\frac{F_{2}}{2} * 22.4\right)+\left(\frac{F_{3}}{3} * 19.2\right) \\
+ & \sum_{i=1}^{n} \operatorname{DeVI}+\left(\frac{F_{4}}{4} * 47.5\right)+\left(\frac{F_{5}}{3} * 32.3\right)+\left(\frac{F_{6}}{2} * 20.1\right)+\sum_{i=1}^{n} \operatorname{SEVI} \\
& -\left(\frac{F_{7}}{5}\right) * 79.6-\left(\frac{F_{8}}{4}\right) * 20.3
\end{aligned}
$$

The cardinality of each factor was determined in such a way that positive values would increase social vulnerability, while negative values would decrease the overall value.

In order to detect spatial differences in the levels of social vulnerability across the studied area, the LoSoVI scores for each territorial unit were mapped in ArcGIS based on five categories, according to the standard deviation from the mean. Negative values represent low vulnerability while positive values denote a high degree of vulnerability (Table 4). 
Table 3. The significant components and their adjusted loadings used to assess local social vulnerability in Romania.

\begin{tabular}{|c|c|c|c|c|c|}
\hline & Component & $\begin{array}{l}\text { Percent Variance } \\
\text { Explained }\end{array}$ & Dominant Variables & Component Loading & Sign \\
\hline \multirow{12}{*}{$\begin{array}{l}\text { Built } \\
\text { Vulnerability Index }\end{array}$} & \multirow{5}{*}{ Housing facilities } & \multirow{5}{*}{43.977} & Share of households with access to piped water & -0.963 & \multirow{5}{*}{-} \\
\hline & & & Share of households with access to sewage networks & -0.964 & \\
\hline & & & Share of households with a central heating system & -0.803 & \\
\hline & & & Share of households with a kitchen area & -0.676 & \\
\hline & & & Share of households with a fixed bath & -0.966 & \\
\hline & \multirow{2}{*}{ Quality of living } & \multirow{2}{*}{16.133} & Average number of people per household & 0.859 & \multirow{2}{*}{+} \\
\hline & & & Number of housing units per square kilometre & -0.846 & \\
\hline & \multirow{3}{*}{ Quality of housing } & \multirow{3}{*}{11.607} & Number of houses constructed from wood & 0.654 & \multirow{3}{*}{+} \\
\hline & & & Number of houses with a reinforced structure & -0.586 & \\
\hline & & & Population density & 0.691 & \\
\hline & $\begin{array}{c}\text { Cumulative } \\
\text { variance explained }\end{array}$ & 71.717 & & & \\
\hline & $\begin{array}{l}\text { Kaiser-Mayer-C } \\
\text { of Sampling Ac } \\
\text { Bartlett's Test of }\end{array}$ & $\begin{array}{l}\text { Measure } \\
\text { dacy } 0.815 \\
\text { ericity } 0.000\end{array}$ & $\begin{array}{l}\text { Extraction Method: Principal Component } \\
\text { Varimax with Kaiser Normalization. Rotati }\end{array}$ & $\begin{array}{l}\text { nalysis. Rotation Method: } \\
\text { converged in } 5 \text { iterations. }\end{array}$ & \\
\hline \multirow{10}{*}{$\begin{array}{c}\text { Demographic } \\
\text { Vulnerability Index }\end{array}$} & \multirow{3}{*}{ Family structure } & \multirow{3}{*}{40.211} & Share of population aged 65 years and above & 0.916 & \multirow{3}{*}{+} \\
\hline & & & Demographic dependency ratio & 0.825 & \\
\hline & & & Share of widows within the female population & 0.913 & \\
\hline & \multirow{3}{*}{$\begin{array}{l}\text { Demographic vitality and } \\
\text { ethnicity }\end{array}$} & \multirow{3}{*}{18.870} & Share of Roma population & 0.633 & \multirow{3}{*}{+} \\
\hline & & & Number of births per 1000 persons & 0.794 & \\
\hline & & & Share of the population under 5 years old & 0.746 & \\
\hline & \multirow{2}{*}{ Gender and mobility } & \multirow{2}{*}{14.211} & Net international migration rate & 0.888 & \multirow{2}{*}{+} \\
\hline & & & Share of women from the total population & 0.601 & \\
\hline & $\begin{array}{c}\text { Cumulative } \\
\text { variance explained }\end{array}$ & 73.292 & & & \\
\hline & $\begin{array}{l}\text { Kaiser-Mayer-C } \\
\text { of Sampling Ac } \\
\text { Bartlett's Test of }\end{array}$ & $\begin{array}{l}\text { Measure } \\
\text { lacy } 0.637 \\
\text { ericity } 0.000\end{array}$ & \multicolumn{3}{|c|}{$\begin{array}{l}\text { Extraction Method: Principal Component Analysis. Rotation Method: } \\
\text { Varimax with Kaiser Normalization. Rotation converged in } 5 \text { iterations. }\end{array}$} \\
\hline
\end{tabular}


Table 3. Cont.

\begin{tabular}{|c|c|c|c|c|c|}
\hline & Component & $\begin{array}{l}\text { Percent Variance } \\
\text { Explained }\end{array}$ & Dominant Variables & Component Loading & Sign \\
\hline \multirow{11}{*}{$\begin{array}{c}\text { Socio-Economic } \\
\text { Vulnerability Index }\end{array}$} & \multirow{5}{*}{$\begin{array}{l}\text { Education and } \\
\text { accessibility }\end{array}$} & \multirow{5}{*}{56.566} & Percent employed in services & -0.780 & \multirow{5}{*}{-} \\
\hline & & & Share of population with a university education & -0.610 & \\
\hline & & & Access to major public road networks & -0.831 & \\
\hline & & & Access to railway transportation & -0.546 & \\
\hline & & & Illiteracy rate & 0.909 & \\
\hline & \multirow{4}{*}{ Poverty and employment } & \multirow{4}{*}{14.438} & Per capita income & -0.871 & \multirow{4}{*}{-} \\
\hline & & & Entrepreneurial activity rate & -0.700 & \\
\hline & & & Employment rate & -0.698 & \\
\hline & & & Tax collection rate at local budget level & -0.901 & \\
\hline & $\begin{array}{c}\text { Cumulative } \\
\text { variance explained }\end{array}$ & 71.004 & & & \\
\hline & \multicolumn{2}{|c|}{$\begin{array}{l}\text { Kaiser-Mayer-Olkin Measure } \\
\text { of Sampling Adequacy } 0.827 \\
\text { Bartlett's Test of Sphericity } 0.000\end{array}$} & \multicolumn{2}{|c|}{$\begin{array}{l}\text { Extraction Method: Principal Component Analysis. Rotation Method: } \\
\text { Varimax with Kaiser Normalization. Rotation converged in } 3 \text { iterations. }\end{array}$} & \\
\hline
\end{tabular}

Note: The symbol indicates whether the used variable increases or decreases social vulnerability ( $+=$ increases vulnerability, $-=$ decreases social vulnerability). 
Table 4. The vulnerability level classification based on the standard deviation.

\begin{tabular}{cc}
\hline Standard Deviation & Level of Vulnerability \\
\hline$>1.5 \sigma$ & Very high \\
0.5 to 1.5 & High \\
-0.5 to 0.5 & Moderate \\
-1.5 to -0.5 & Low \\
$<-1.5$ & Very low \\
\hline
\end{tabular}

After performing the PCA analysis, a model of Geographically Weighted Regression (GWR) was used to explore the spatial relationship between communities directly affected by floods and localities with high and very high LoSoVI values. GWR is a local spatial statistical technique that assumes non-stationarity within relationships-i.e., that is the relationship between the dependent and the explanatory variables changes from location to location [49]. Thus the regression coefficient $\beta_{\mathrm{k}}$ takes different values for each location. The equation for the regression model is described below.

$$
\begin{gathered}
y_{i}=\beta_{0}(i)+\beta_{1}(i) x_{1 i}+\beta_{2} \text { (i) } x_{2 i}+\ldots+\beta_{n} \text { (i) } x_{n i}+\varepsilon_{1}, \\
\beta^{\prime}(i)=\left(X^{T} W(i) X\right)^{-1} X^{T} W(i) Y,
\end{gathered}
$$

where $i$ denotes the coordinates of the points in space and $W(i)$ is a matrix of weights specific to location $i$ constructed in such a way, that observations nearer to $i$ are given a greater weight than others. $\beta$ represents the vector of global parameters to be estimated, $y$ is a vector of observations on the dependent variable and $X$ is a matrix of independent variables.

GWR can be used for uncovering spatial relationships or associations overlooked by OLS. If the relationship does not vary across space, the global model is an appropriate tool for processing the data. Usually, the Akaike's Information Criteria (AICc) is used to compare the overall results from a global OLS linear regression model with those from the local GWR model [50]. AICc can be defined as follows:

$$
\text { AICc }=-2 \log \text { Likelihood }=2 k=2 k(k+1) /(n-k-1),
$$

where $k$ is the number of estimated parameters in the model (i.e., the number of variables +1 , to include the intercept) and $n$ is the number of observations in the dataset. If the GWR AICc's value is smaller than the OLS, the value is considered to be the best fit for the model. Besides the AICc information, a set of parameter estimates (local coefficients for each explanatory variable) and associated diagnostics (standard errors, Cook's D statistics, local $\mathrm{R}^{2}$ statistics) are the major outputs which can be visualized with the help of a GIS platform.

By using the GWR4 software to perform the analysis, we have adopted a split-GWR framework using data on just the high and very high social vulnerability communities. This approach has also been adopted by Shoff and Yang [51] while analysing the spatially varying predictors of teenage birth rates in metropolitan and non-metropolitan areas in the USA. GWR was originally developed for spatial point data analysis but it can also be applied to areal data by using the geographical centroids of the analysed areas [51]. One of the method's most important strengths is that it allows for the interpolation of values belonging to spatial points not included in the dataset [52]. During the computerization, the adaptive bi-square kernel method was applied for geographical weighting in order to estimate local coefficients and a bandwidth size as the observation points of the studied region consist of irregular distances [53]. The distinctive feature of this method is that its bandwidth can adapt to the number and density of data points, not requiring that the spatial data points are from a contiguous area, so the spatially continuous character of the observations is not a prerequisite for estimating GWR anymore. The golden-section search was also applied to automatically search for the optimal bandwidth size and the correction of the Akaike Information Criterion (AICc) allowed for an adaptation for selecting 
the optimum bandwidth [50]. Finally, the GWR results were compared to those of the OLS in order to see which model fits the current analysis better.

\section{Results}

\subsection{Measuring Social Vulnerability}

By applying the Principal Component Analysis, over a set of 27 variables and a total of 3181 settlements, we have managed to uncover eight latent factors grouped into three categories: Built Environment Vulnerability Index (BEVI), including housing facilities, quality of living, and quality of housing; Demographic Vulnerability Index (DeVI), which incorporates the family structure, demographic vitality and ethnicity, gender, and mobility; and the Socio-Economic Vulnerability Index (SEVI) encompassing education and accessibility, as well as income and employment. The three dimensions of vulnerability have explained $71.7 \% ; 73.2 \%$ respectively $71 \%$ of the variance within a middling value for the Kaiser-Meyer-Olkin (KMO) Measure of Sampling Adequacy. On the other hand, Bartlett's test also indicates a high probability of significant relationships existing between the analysed variables $(p<0.001)$ (Table 3$)$.

By analysing the values of the resulted vulnerability scores it must be noted that $34.2 \%$ of settlements are characterized by low and very low vulnerability ( -1.5 to $0.5 \mathrm{Std}$. Dev.) while $28.4 \%$ fall into categories labelled with high and very high degrees of vulnerability (0.5-1.5 Std. Dev.). We have obtained similar results by adopting the original methodology proposed by Cutter et al. [1], regarding the identification of the least vulnerable and most vulnerable settlements (Figure 3a,b). However, since in the current analysis we have also introduced factors regarding the built environment, specific areas falling into these two extreme categories might differ slightly. According to the factor scores, the most vulnerable areas are to be found-besides the eastern parts of the country-in the southwestern and north-western areas. Within these territories, social vulnerability is mainly impacted by the high proportion of elderly people (with a higher share in the south-western and western parts), by the limited access to resources, and lack of infrastructure. To this, we can add the presence of a high illiteracy rate and a low level of education but also the fact that a relatively high share of the population is working in (subsistence) agriculture-an economic sector highly sensitive to environmental conditions. Low wages and high levels of poverty are just contributing to the social vulnerability of people living in these areas. The only exceptions to the rule are medium-sized cities and suburban localities where job opportunities, the quality of life, and educational opportunities are more favourable, thus lowering the chance of people becoming socially vulnerable (Figure 3b). Looking into the factor scores, we can see that the localities most in need of assistance are Bărbulești from Ialomița county, Pardoși and Chiliile from Buzău county, Bulzeștii de Sus from Hunedoara county, along with Ohaba and Bunila from Alba county.

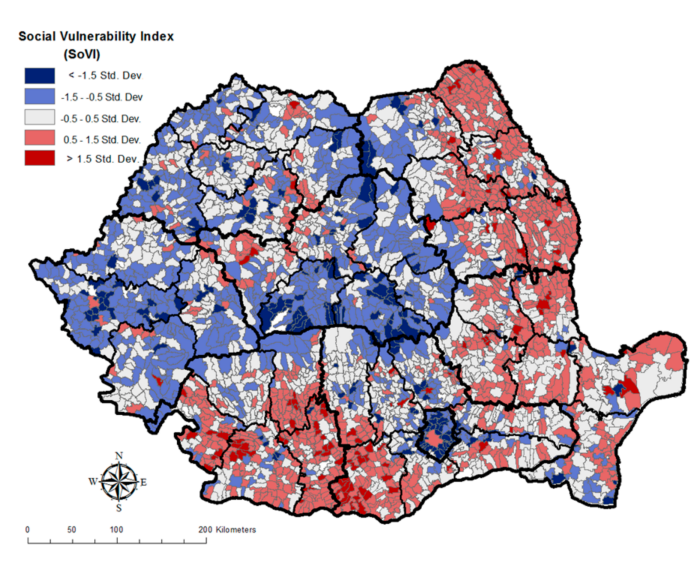

(a)

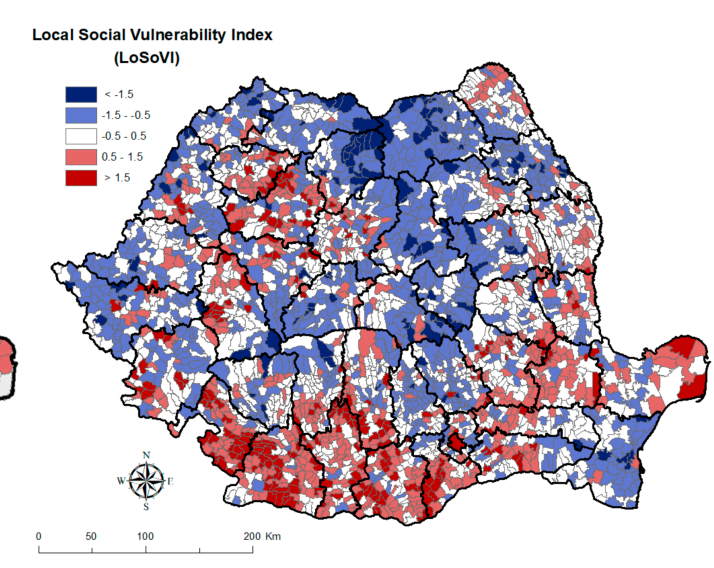

(b)

Figure 3. The comparison between the Social Vulnerability Index scores in Romania calculated without weighting (a) and using a specific weighting method (b) for 2011. 
The least vulnerable localities, on the other hand, are concentrated in the northern and central parts of the country, but we could also find some homogenous areas in the south-eastern and western parts, sharing some key characteristics. First of all, the population in these areas has a relatively good access to major public roads and the railway system, disposes of favourable housing facilities and has a relatively high quality of living, in many cases well above the national average. Here we can also add the high demographic vitality (high share of children under 15 years) and the high degree of mobility characterizing mainly the eastern and central parts of the country. According to the factor scores, the least vulnerable areas are Vicovu de Sus, the largest commune from Suceava county, declared a town by Law 83 in 2004, characterized by a dynamic development in recent years; Sângeorz-Băi from Bistrița-Năsăud county, a well-known balneo-climateric resort; Cristian from Sibiu county, located in the suburban area of Sibiu Municipality. It must be mentioned that all of the communes characterized by a low SoVI ${ }^{\circledR}$ index [36] can also be found in this category, like Moșnița Nouă and Remetea Mare from Timiș county; Otopeni, Corbeanca and Mogoșoaia from Ilfov county as well as Gârbău from Cluj county—all of the parts of the greater suburban areas of Timișoara, Bucharest and Cluj-Napoca urban agglomerations (Figure 3b). These settlements represent 3.9\% of the study units (124 communes and municipalities). It is worth mentioning that the level of economic development is not in all cases inversely proportional with the vulnerability to natural hazards since a high level of development can greatly increase the level of internal inequalities, meaning that highly developed urban agglomerations are not necessarily areas with a low level of social vulnerability [54]. This can be well observed in large urban areas (of more than 200,000 inhabitants) where the high population density and the concentration of economic activities increase the vulnerability of the built environment. Furthermore, the existence of wealth-poverty dichotomies, social inequalities, and social segregation within cities can amplify their exposure to social risks [36]. According to the LoSoVI index, especially Timișoara, Craiova, Brăila and the capital—Bucharest—are labelled with high values of social vulnerability, while others like Constanța, Cluj-Napoca and Iaşi belong to intermediate categories, all of them being surrounded by areas with a low level of social vulnerability. As we could observe, some of the most important factors influencing social vulnerability are the levels of economic development, education, and occupation status, but also housing facilities, although these aspects are not only valid for Romania. By integrating these indicators into the vulnerability assessment model, similar results have been achieved by Holand et al. [18] for the municipalities of Norway, by Guillard et al. [41] for Portugal, by Hummell et al. [42] for Brazil, to name just a few in a wider context.

\subsection{Geographically Weighted Regression Results}

The GWR analysis was performed using the GWR4 software. For the dependent variable we have used the number of people affected by flood hazards, the generated eight (especially the high and very high) LoSoVI factors acting as independent variables. The Pearson correlation revealed that a total of five out of eight variables with a p-value less than 0.05 show a significant correlation with frequently flooded communities: housing facilities, quality of housing, family structure, education and accessibility, income, and employment. In order to examine the multicollinearity between the selected variables, the variance inflation factor (VIF) was checked. If the VIF is less than 10, it can be stated that no multicollinearity exists, which means that it will not influence the stability of the parameter estimates significantly [55]. As the VIF scores range between 1.348 and 3.005, we used all five LoSoVI scores for the regression model (Table 5).

Table 5. The selection of variables using correlation and the multicollinearity test.

\begin{tabular}{ccccc}
\hline LoSoVI Scores & Pearson Correlation & Sig. (2-Tailed) & VIF & N \\
\hline Housing facilities & $-0.340^{* *}$ & 0.000 & 3.005 & 408 \\
Quality of housing & $0.283^{* *}$ & 0.000 & 1.348 & 408 \\
Family structure & $-0.146^{* *}$ & 0.003 & 1.544 & 408 \\
Education and accessibility & $0.312^{* *}$ & 0.000 & 2.817 & 408 \\
Income and employment & $0.265^{* *}$ & 0.000 & 2.119 & 408 \\
\hline
\end{tabular}

** Correlation is significant at 0.01 level (2-tailed). 
The OLS global model explained about $43 \%$ (adjusted $\mathrm{R}^{2}=0.43$ ) of the variation in the numbers of the population directly affected by flood hazards, with an AICc value of 9139.28. At the same time, the calibrated results obtained by calculating the GWR have shown a significant improvement of the global model. By comparing the AICc values for the two models, we can observe a significant reduction from 9139.28 to 8816.42 , the difference of 82.48 implying a strong improvement in adequacy and proving at the same time that the GWR model is much more suitable for analysing the respective data. Since the AICc is a measure of spatial collinearity within the dataset, the lower the value of AICc, the better the model will fit the observed data. Moreover, the local $\mathrm{R}^{2}$ value of 0.78 also suggests an improvement in the performance of the model (Table 6). Thus, the explanatory power of the local model (GWR) is higher than that of the OLS model.

Table 6. The results of the Ordinary Least Square (OLS) and Geographically Weighted Regression (GWR) analysis models.

\begin{tabular}{ccc}
\hline Fitness Parameter & OLS & GWR \\
\hline AICc & 9139.28 & 8816.42 \\
Coefficient determination $\mathrm{R}^{2}$ & 0.444 & 0.834 \\
Adjusted $\mathrm{R}^{2}$ & 0.436 & 0.787 \\
\hline
\end{tabular}

Figure 4 shows the distribution of Local $\mathrm{R}^{2}$ values (Figure $4 \mathrm{a}$ ) as well as the territorial distribution of the standard deviation of residuals (Figure $4 \mathrm{~b}$ ). In the case of the Local $\mathrm{R}^{2}$, the higher the value, the better the performance of the local model. In our case, $68 \%$ of the analysed communities have relatively high $\mathrm{R}^{2}$ values (between 0.47 and 0.89 ), which explains why communities characterized by high and very high LoSoVI scores are also the most prone to suffer from flooding. On the other hand, the lower the standard deviation of residuals, the better the GWR model fits the observed data, which, in the case of the analysed regions, explains the relationship between flood hazard and socio-economic aspects.

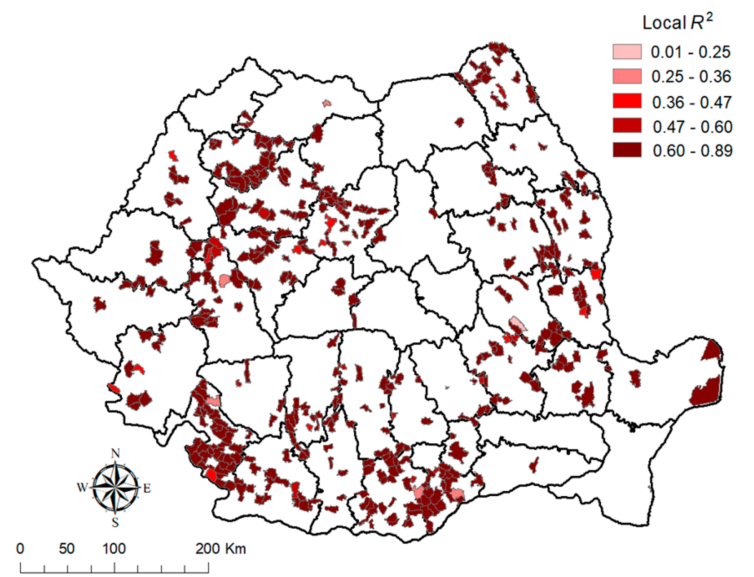

(a)

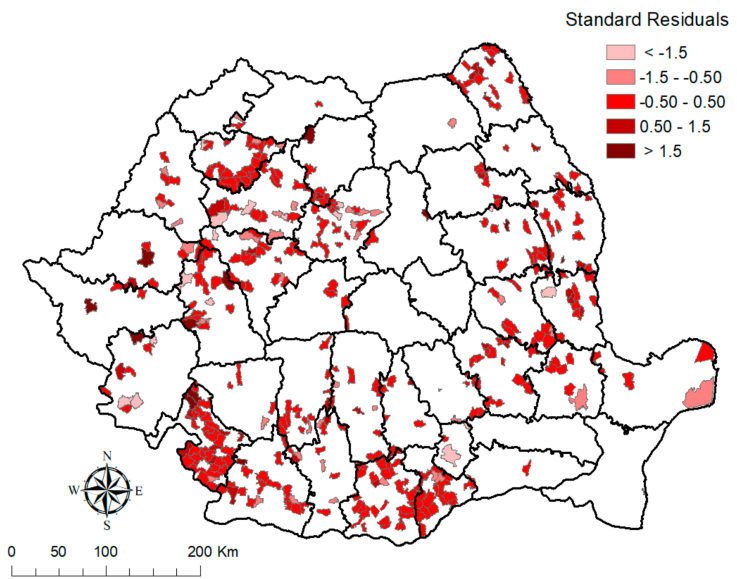

(b)

Figure 4. (a) The spatial distributions of the local $R^{2}$ and (b) the standard deviation of the residuals.

We have found that the relationship between communities directly affected by floods and localities with high and very high LoSoVI values can be investigated over multiple spatial scales by incorporating geographic information into GWR analyses. The improved performance of the GWR over the global regression model was demonstrated by significantly lower values both for the AICc as well as deviance. An additional strength of the GWR method was the ability to explore spatial variability in the relationship between the population directly affected by flooding and explanatory variables like housing facilities and quality of housing, family structure, education and accessibility as 
well as income and employment. The value of local $\mathrm{R}^{2}$ varies between 0.01 and 0.89 , indicating that the GWR model fits the observed y value well. As we have mentioned, the higher the value of the indicator, the better the model fits the data, while lower values indicate that the fit of the model is not unequivocal.

With a few exceptions, most of the settlements included in the analysis have a high explanatory power $\left(R^{2}=0.47\right.$, denoting a value above $\left.47 \%\right)$, while the low values of the residuals representing the difference between the observed and estimated values (Figure $4 \mathrm{~b}$ ) denote a proper fit of the GWR model to the observed data.

\section{Discussion}

Addressing social vulnerability to disaster risks requires the understanding that the social context itself can increase both vulnerability (socio-economic variables), as well as the building of capacities to deal effectively with flood hazards [56]. Eliminating variables which lead to vulnerability (such as a low level of education, high poverty rate and low accessibility to basic infrastructure as well as the imbalanced family structure) and capacity building which include those activities that help people mitigate the impact of a disaster, should represent the most important policy implications. Disaster risk prevention and reduction are crucial to enhance the socio-economic resilience of communities. In the context of climate change, where floods are expected to become more frequent, flood risk mitigation is a major concern of water policies and sustainable development strategies at different spatial scales.

Managing climate change-related risks requires decisions and strategies for adaptation, with implications for future generations, economies, and environments [57]. The most important national document regulating flood risk management in Romania is the National Strategy for Flood Risk Management for the medium and long-term, which was adopted in 2010. This strategy defines the technical, institutional and legal framework for diminishing the negative consequences of floods on socio-economic activities, life and population health, as well as on the environment, for the 2010-2035 period [58]. Romania has a central water management authority, the Romanian Waters National Administration (RWNA) which is responsible for the implementation of the national water management strategy and policies, aspects related to quantitative and qualitative water management as well as the operation of the different management structures. This Authority has 11 regional branches (see Figure 1) organized according to the hydrographic basins of Romania, each with its own Flood Risk Management Plan. These plans address all aspects of flood risk management focusing on prevention, protection, preparedness, including flood forecasts and early warning systems, considering the characteristics of the particular river basin or sub-basin. Flood risk management plans also include actions to promote sustainable land use practices, the improvement of water retention as well as the controlled flooding of certain areas in the case of a flood event [59].

As it could be observed, government agencies-at least on paper-have elaborated and implemented all necessary measures associated with flood risks (prevention). Related to our analysis, the central question is related to policy or planning mechanisms aiming to cope with existing social vulnerabilities, increasing public participation, public relations/communication, and education on flood risk. According to the results of local surveys conducted in Niraj Walley, local authorities are generally aware of their settlements being exposed to a flood event, but usually have no information on multiple problems involved which can be related to social and economic aspects of the built infrastructure, as they have been revealed by the present analysis. As this is the first attempt ever to measure social vulnerability for all settlements in Romania, inserting the main findings into the revised National Strategy for Flood Risk Management, followed by an update of the Flood Risk Management Plans for all the 11 hydrographic districts would have a great added value in increasing the effectiveness of the mentioned documents in diminishing the impact of future floods. Even so, the most important activities for flood risk prevention depend on the affected population, as the responsibilities of local authorities are mainly related to transmitting relevant information in due time and to as many people as possible. With this regard, it must be mentioned that Romania has introduced a compulsory 
insurance system enforced by law no. 260/2008 and law 191/2015, making it compulsory for all Romanian real-estate owners to purchase multi-hazard insurance. The amount of insurance depends on the quality of the building - mostly reflected by the construction type-and not on the probability of exposure to the specific hazard. The mentioned legislation also states that no compensation will be paid from the State Budget to uninsured households. Even though this provision is compulsory for all Romanian real-estate owners, according to the latest available statistics (31 August 2018), the rate of ensured households has barely reached $20 \%$, with higher rates in urban than in rural areas [60]. The low penetration in rural areas is mostly due to a lack of trust regarding insurers, missing information on how to buy insurance, difficulties proving the ownership of properties but also due to the self-assurance of people believing that such a hazard event could not happen to them. According to the survey performed in July 2015, when 741 households were queried in the Niraj Walley (Central Romania) about their perception on natural hazards, only 8.1 percent of the respondents mentioned that they are prepared for all hazardous events, 36.6 percent claimed they can only take the most basic measures, 43.2 percent considered themselves unable to take any action, while 8.5 percent believed that their household could not suffer any hazardous event. These values are all the more surprising when we consider that most settlements have strategic documents elaborated like Defence Plans in case of emergencies, including information on the Local Committee for Emergency Situations, schemes for transmitting information in case of emergency situations at the local scale, defence measures against floods, limits of flooded areas, etc. This makes us realize that it is not enough to publish or disseminate such information on the City Hall website or on posters with textual information or maps regarding flood risk in buildings of the local council, since in this way information does not reach the elderly or people from isolated households which are in the greatest need of help. In this case, the most important task should be overtaken not only by local authorities, but also by other public figures like religious leaders or teachers, by informing people and raising awareness regarding the flood risk. According to the results of the above-mentioned survey, we consider that the best solutions are actions which are held in schools in order to raise awareness and educate the children at an early age. In the case of the elderly, personal contact and giving help in increasing the level of preparedness are of utmost importance. Flood risk adaptation is key for the existence of people in certain areas, enabling them to survive in extreme conditions, such as floods. Therefore, exercises and simulations of flood crises should be organised at regular time intervals in order to train the population at risk. As it could be observed, adaptation to flood risk can be achieved by various hard and soft measures, all contributing to flood risk mitigation. At the same time, LoSoVI can provide the basis for discussing the main causes of risk and vulnerability, mitigation measures, preparedness, response planning as well as recovery.

\section{Conclusions}

In recent years, there has been an increased interest towards initiatives aiming to reduce the impact of hazards, not just from a physical perspective, but also from a social perspective. Despite the absence of a generally accepted definition and an agreed-upon methodology for the measurement of social vulnerability, we can conclude that an important number of initiatives providing different methodological approaches and indicators offer a valuable contribution to its assessment. It is a universally accepted fact that there is neither a single common approach nor a universal catalogue of vulnerability indicators: vulnerability is highly context-specific in terms of the socio-economic, demographic, political, and cultural contexts. Furthermore, considering the temporal and spatial variations of social vulnerability, a one-size-fits-all approach for increasing preparedness, improving response, and facilitating recovery may be the least effective for reducing it [61].

This paper was aimed to provide an assessment of social vulnerability in Romanian settlements by applying the SoVI method in a local context. Using GIS-based local models and global statistics to explore the relationship between populations exposed to flood hazards and settlements characterized by high vulnerability scores, we were able to detect and extract certain key information pieces concerning non-stationarity in spatial data. By comparing the results regarding the adequacy of 
global OLS and local GWR models with certain parameter estimates, this paper has managed to explicitly demonstrate that within spatial data, the relationship is non-static across geographic space. The results from our analysis complement the main findings and existing debates in contemporary literature in many ways.

First, the conducted research represents the first in-depth attempt to quantify community-level vulnerability to flood hazards in Romania. The path dependency of some localities, the specific historical, social and economic factors have put their mark on the evolution of social vulnerability, especially on variables like the ageing of the population, occupation and income levels. These factors also represent the main origin of socio-spatial inequalities which have now been reflected in the territorial distribution of the LoSoVI model. In general, a high level of vulnerability associated with a low level of resilience characterizes peripheral rural areas, which are further affected by natural hazards, especially floods (eastern and north-western parts of rural Romania). What is more, due to the high rate of poverty and limited access to resources and services, these areas are often associated with low levels of education and lack of sanitation facilities, decreasing the ability to cope with the impact of natural hazards. In this sense, their present status may very well give serious reason for concern. As the study has confirmed, even the most developed urban areas can be vulnerable in the face of natural disasters (generally due to the high population density), indicating that large urban agglomerations do not necessarily have low levels of social vulnerability and that economic development is not always inversely proportional to vulnerability, although as mentioned earlier, the respective communities have much better capabilities to cope with-, to resist-, and to recover from losses.

Second, the developed GWR model can be used to carry out predictions for flood hazard damages among highly vulnerable population groups in Romania.

Third, from the point of view of sustainable spatial planning, the present study is particularly important because by capturing the spatial characteristics of social vulnerability, the above in-depth analysis may offer a viable and integrative practical guide to authorities and policy-makers for taking the necessary measures in order to diminish social vulnerability in specific areas. Thus, the analysis of vulnerability at the local level enables the identification of settlements in need of financial resources in order to diminish the negative impact of natural hazards. By assessing the social vulnerability of a certain area we can determine its unique position in relation to flood hazards. This, in turn, can serve as the starting point for local planners and decision-makers in identifying weak points to be included into future development strategies, thus, improving the communities' own ability to cope with the effects of flood hazards. Further on, the collaboration between researchers of flood hazards and local practitioners regarding the effective vulnerability assessment can contribute not only to the sharing of knowledge, but can also help facilitate the insertion of specific local needs into local policy decisions.

Although the analysis provides the possibility to explore fundamental social-, environmentaland economic phenomena using an innovative approach, due to the limited access to reliable and up-to-date economic and environmental data at the local level, it is still not able to provide us with an overall assessment on social vulnerability. At the same time, the final results of such analyses are also very much dependent not only on the used variables, selected methods and weighting schemes, but also on the different interpretations of the concept of vulnerability. The present analysis has managed to capture some of the social aspects which can be considered essential building blocks in the overall assessment of physical vulnerability, therefore—as Holand et al. mentioned [18]—differing results should be seen as complementarities rather than contradictions in applying the different models.

Funding: This research received no external funding.

Conflicts of Interest: The author declares no conflict of interest. 


\section{Abbreviations}

$\begin{array}{lllll}\text { AB: Alba } & \text { AG: Argeș } & \text { AR: Arad } & \text { B: București } & \text { BC: Bacău } \\ \text { BH: Bihor } & \text { BN: Bistrița-Năsăud } & \text { BR: Brăila } & \text { BT: Botoșani } & \text { BV: Brașov } \\ \text { BZ: Buzău } & \text { CJ: Cluj } & \text { CL: Călărași } & \text { CS: Caraș-Severin } & \text { CT: Constanța } \\ \text { CV: Covasna } & \text { DB: Dâmbovița } & \text { DJ: Dolj } & \text { GJ: Gorj } & \text { GL: Galați } \\ \text { GR: Giurgiu } & \text { HD: Hunedoara } & \text { HR: Harghita } & \text { IF: Ilfov } & \text { IL: Ialomița } \\ \text { IS: Iași } & \text { MH: Mehedinți } & \text { MM: Maramureș } & \text { MS: Mureș } & \text { NT: Neamț } \\ \text { OT: Olt } & \text { PH: Prahova } & \text { SB: Sibiu } & \text { SJ: Sălaj } & \text { SM: Satu Mare } \\ \text { SV: Suceava } & \text { TL: Tulcea } & \text { TM: Timiș } & \text { TR: Teleorman } & \text { VL: Vâlcea } \\ \text { VN: Vrancea } & \text { VS: Vaslui } & & & \end{array}$

\section{References}

1. Cutter, S.L.; Boruff, B.J.; Shirley, W.L. Social vulnerability to environmental hazards. Soc. Sci. Quart. 2003, 84, 242-261. [CrossRef]

2. Rygel, L.; O'sullivan, D.; Yarnal, B. A method for constructing a social vulnerability index: An application to hurricane storm surges in a developed country. Mitig. Adapt. Strateg. Glob. Chang. 2006, 11, 741-764. [CrossRef]

3. Willis, I.; Fitton, J. A review of multivariate social vulnerability methodologies: A case study of the River Parrett catchment, UK. Nat. Hazards Earth Syst. Sci. 2016, 16, 1387-1399. [CrossRef]

4. Fekete, A. Validation of social vulnerability index in context to river floods in Germany. Nat. Hazards Earth Syst. Sci. 2009, 9, 393-403. [CrossRef]

5. Cutter, S.L.; Finch, C. Temporal and spatial changes in social vulnerability to natural hazards. Proc. Natl. Acad. Sci. USA 2008, 105, 2301-2306. [CrossRef] [PubMed]

6. Tate, E. Social vulnerability indices: A comparative assessment using uncertainty and sensitivity analysis. Nat. Hazards 2012, 63, 325-347. [CrossRef]

7. Eakin, H.; Luers, A.L. Assessing the vulnerability of social environmental systems. Annu. Rev. Environ. Resour. 2006, 31, 369-394. [CrossRef]

8. Füssel, H.M.; Klein, R.J.T. Climate change vulnerability assessment: An evolution of conceptual thinking. Clim. Chang. 2006, 75, 301-329. [CrossRef]

9. Hewitt, K.; Burton, I. The Hazardousness of a Place: A Regional Ecology of Damaging Events, 1st ed.; University of Toronto Press: Toronto, ON, Canada, 1971; ISBN 100802030834.

10. White, G.F. Natural Hazards: Local, National, Global, 1st ed.; Oxford University Press: Oxford, UK, 1976; ISBN 100195017579.

11. Hewitt, K. Interpretation of Calamity from the Viewpoint of Human Ecology, 1st ed.; George Allen \& Unwin Ltd.: London, UK, 1983; ISBN 0-04-301160-8.

12. Cutter, S.L.; Emrich, C.T.; Webb, J.J.; Morath, D.P. Social vulnerability to climate variability hazard: A review of the literature. Final Rep. Oxfam. Am. 2009, 5, 1-44.

13. Turner, B.L.; Kasperson, R.E.; Matson, P.A.; McCarthy, J.J.; Corell, R.W.; Christensen, L.; Eckley, N.; Kasperson, J.X.; Leurs, A.; Martello, M.L.; et al. Framework for vulnerability analysis in sustainability science. Proc. Natl. Acad. Sci. USA 2003, 100, 8074-8079. [CrossRef] [PubMed]

14. Kates, R.W. The Interaction of Climate and Society. Available online: http://rwkates.org/pdfs/a1985.01.pdf (accessed on 21 September 2016).

15. Cutter, S.L. Vulnerability to environmental hazards. Prog. Hum. Geogr. 1996, 20, 529-539. [CrossRef]

16. Birkmann, J. Measuring vulnerability to promote disaster-resilient societies and to enhance adaptation: Conceptual frameworks and definitions. In Measuring Vulnerability to Natural Hazard. Towards Disaster Resilience Societies, 2nd ed.; Birkmann, J., Ed.; United Nations University Press: Bonn, Germany, 2013; pp. 9-80. ISBN 109280812025.

17. Holand, I.S.; Lujala, P.; Rød, J.K. Social vulnerability assessment for Norway: A quantitative approach. Nor. Geogr. Tidsskr. 2011, 65, 1-7. [CrossRef]

18. Chen, W.F.; Cutter, S.L.; Emrich, C.T.; Shi, P. Measuring social vulnerability to natural hazards in the Yangtze River Delta region, China. Int. J. Disaster Risk Reduct. 2013, 4, 169-181. [CrossRef] 
19. Cutter, S.L.; Morath, D.P. The evolution of Social Vulnerability Index (SoVI). In Measuring Vulnerability to Natural Hazards. Towards Disaster Resilience Societies, 2nd ed.; Birkmann, J., Ed.; United Nations University Press: Bonn, Germany, 2013; pp. 304-321. ISBN 109280812025.

20. Rufat, S.; Tate, E.; Burton, C.; Maroof, S.A. Social vulnerability to floods: Review of case studies and implications for measurement. Int. J. Disaster Risk Reduct. 2015, 14, 470-486. [CrossRef]

21. Mwale, F.D.; Adeloye, A.J.; Beevers, L. Quantifying vulnerability of rural communities to flooding in SSA: A contemporary disaster management perspective applied to the Lower Shire Valley, Malawi. Int. J. Disaster Risk Reduct. 2015, 12, 172-187. [CrossRef]

22. Frigerio, I.; Amicis, M. Mapping social vulnerability to natural hazards in Italy: A suitable tool for risk mitigation strategies. Environ. Sci. Poicy 2016, 63, 187-196. [CrossRef]

23. Armaș, I.; Toma-Dănilă, D.; Ionescu, R.; Gavriș, A. Vulnerability to earthquake hazard: Bucharest case study, Romania. Int. J. Disaster Risk Sci. 2017, 8, 182-195. [CrossRef]

24. Bănică, A.; Roșu, L.; Muntele, I.; Grozavu, A. Towards urban resilience: A multi-criteria analysis of seismic vulnerability in Iași city (Romania). Sustainability 2017, 9, 270. [CrossRef]

25. Li, K.; Li, G.S. Vulnerability assessment of storm surges in the coastal area of Guangdong Province. Nat. Hazards Earth Syst. Sci. 2011, 11, 2003-2010. [CrossRef]

26. Kuhlicke, C.; Scolobig, A.; Tapsell, S.; Steinführer, A.; De Marchi, B. Contextualizing social vulnerability: Findings from case studies across Europe. Nat. Hazards 2011, 58, 789-810. [CrossRef]

27. Ashley, S.T.; Ashley, W.S. Flood fatalities in the United States. J. Appl. Meteorol. Climatol. 2008, 47, 805-818. [CrossRef]

28. Doocy, S.; Daniels, A.; Murray, S.; Kirsch, T.D. The human impact of floods: A historical review of events 1980-2009 and systematic literature review. PloS Curr. 2013. [CrossRef] [PubMed]

29. Lowe, D.; Ebi, K.L.; Forsberg, B. Factors increasing vulnerability to health effects before, during and after floods. Int. J. Environ. Res. Public Health 2013, 10, 7015-7067. [CrossRef] [PubMed]

30. Ajibade, I.; McBean, G.; Bezner-Kerr, R. Urban flooding in Lagos, Nigeria: Patterns of vulnerability and resilience among women. Glob. Environ. Chang. 2013, 23, 1714-1725. [CrossRef]

31. Stângă, I.C.; Grozavu, A. Quantifying human vulnerability in rural areas: case study of Tutova Hills (Eastern Romania). Nat. Hazards Earth Syst. Sci. 2012, 12, 1987-2001. [CrossRef]

32. Armaș, I.; Gavriș, A. Social vulnerability assessment using spatial multi-criteria analysis (SEVI model) and the Social Vulnerability Index (SoVI model)—A case study for Bucharest, Romania. Nat. Hazards Earth Syst. Sci. 2013, 13, 1481-1499. [CrossRef]

33. Bănică, A.; Muntele, I. Urban vulnerability and resilience in post-communist Romania (Comparative case studies of Iasi and Bacau cities and Metropolitan areas). Carpath. J. Earth Env. 2015, 4, 159-171.

34. Constantin, V.; Ștefănescu, L.; Kantor, C.M. Vulnerability assessment methodology: A tool for policy makers in drafting a sustainable development strategy of rural mining settlements in the Apuseni Mountains, Romania. Environ. Sci. Policy 2015, 52, 129-139. [CrossRef]

35. Török, I. Assessment of social vulnerability to natural hazards in Romania. Carpath. J. Earth Env. 2017, 12, 549-562.

36. Marinescu, M.; Stanciu, C.; Marinescu, G. Four important natural hazards from Romania. Romanian J. Earth Sci. 2010, 84, 113-115.

37. Queste, L.; Lauwe, P. User needs: Why we need indicators. In Measuring Vulnerability to Natural Hazards. Towards Disaster Resilience Societies, 2nd ed.; Birkmann, J., Ed.; United Nations University Press: Bonn, Germany, 2013; pp. 103-115.

38. National Institute of Statistics, Romania-INS. Available online: www.insse.ro (accessed on 18 July 2018).

39. Nardo, M.; Saisana, M.; Saltelii, A.; Tarantola, S.; Hoffman, A.; Giovanni, E. Handbook of Constructing Composite Indicators. Methodology and User Guide; OECD Statistics Working Papers; OECD: Paris, France, 2005.

40. Guillard, G.C.; Cutter, S.L.; Emrich, C.T.; Zezere, J.L. Application of Social Vulnerability Index (SoVI) and delineation of natural risk zones in Greater Lisbon, Portugal. J. Risk Res. 2015, 18, 651-674. [CrossRef]

41. Hummell, L.; Cutter, S.L.; Emrich, C.T. Social vulnerability to natural hazards in Brazil. Int. J. Disaster Risk Sci. 2016, 7, 111-122. [CrossRef]

42. Mazumdar, J.; Kumar, S. Socioeconomic and infrastructural vulnerability indices for cyclones in the eastern coastal states of India. Nat Hazards 2016, 82, 1621-1643. [CrossRef] 
43. Huynh, L.T.M.; Stringer, L.C. Multi-scale assessment of social vulnerability to climate change. An empirical study in coastal Vietnam. Clim. Risk Manag. 2018, 20, 165-180. [CrossRef]

44. Kazmierczak, A.; Cavan, G. Surface water flooding risk to urban communities: Analysis of vulnerability, hazard and exposure. Landsc. Urban Plan. 2011, 103, 185-197. [CrossRef]

45. Hutchesion, G.; Sofroniou, N. The Multivariate Social Scientist: Introductory Statistics Using Generalized Linear Models, 1st ed; SAGE Publications: London, UK, 1999; ISBN 100761952012.

46. Wood, N.J.; Burton, C.G.; Cutter, S.L. Community variations in social vulnerability to Cascadia-related tsunamis in the US Pacific Northwest. Nat. Hazards 2010, 52, 369-389. [CrossRef]

47. Bjarnadottir, S.; Li, Y.; Stewart, M.G. Social vulnerability index for coastal communities at risk to hurricane hazard and changing climate. Nat. Hazards 2011, 59, 1055-1075. [CrossRef]

48. Solangaarachchi, D.; Griffin, A.; Doherty, M.D. Social vulnerability in the context of bushfire risk at the urban-bush interface in Sydney: A case study of the Blue Mountains and Ku-ring-gai local council areas. Nat. Hazards 2012, 64, 1873-1898. [CrossRef]

49. Nkeki, F.D.; Osirike, A.B. Gis-based local spatial statistical model of cholera occurrence: using geographically weighted regression. J. Geogr. Inf. Syst. 2013, 5, 531-542. [CrossRef]

50. Akaike, H. Akaike, H. A new look at the statistical model identification. In Selected Papers of Hirotogu Akaike, 1st ed.; Parzen, E., Tanate, K., Kitagawa, G., Eds.; Springer: New York, NY, USA, 1974; pp. 215-223. ISBN 978-1-4612-7248-9.

51. Shoff, C.; Yang, T.C. Spatially varying predictors of teenage birth rates among counties in the United States. Demogr. Res. 2012, 27, 377-418. [CrossRef] [PubMed]

52. Fotheringham, A.S.; Brunsdon, C.; Charlton, M. Geographically Weighted Regression: The Analysis of Spatially Varying Relationship, 1st ed.; Wiley: New York, NY, USA, 2002; ISBN 0471496162.

53. Nakaya, T.; Charlton, M.; Yao, J.; Fotheringham, A.S. GWR4.09 User Manual: Windows Application For Geographically Weighted Regression Modelling. Available online: https:/ /raw.githubusercontent.com/ gwrtools/gwr4/master/GWR4manual_409.pdf (accessed on 14 September 2017).

54. Huang, J.; Su, F.; Zhang, P. Measuring social vulnerability to natural hazards in Beijing-Tianjin-Hebei Region, China. Chin. Geogr. Sci. 2015, 25, 472-485. [CrossRef]

55. O'brien, R.M. A caution regarding rules of thumb for variance inflation factors. Qual. Quant. 2007, 41, 673-690. [CrossRef]

56. Maghura, E.; Manyena, B.; Collins, A.E. An approach for measuring social vulnerability in context: The case of flood hazards in Mazurabani district, Zimbabwe. Geoforum 2017, 86, 103-117.

57. IPCC. Summary for policymakers. Available online: http://www.ipcc.ch/report/ar5/wg2/ (accessed on 18 September 2018).

58. MMAP. Strategia Nationala de management al riscului la inundatii pe termen mediu si lung. Available online: http://www.mmediu.ro/app/webroot/uploads/files/2012-01-10_risc_inundatii_ hg846din2010aprobaresnmri.pdf (accessed on 17 September 2018).

59. Radulescu, D.; Bogdan, I.M.; Dumitrache, R.; Barbu, C.E. Flood risk management objectives and Romanian cataloque of potential measures for flood prevention, protection and mitigation. Available online: https: / / www.paidromania.ro/statistici-anuale (accessed on 16 September 2018).

60. PAID Romania. Available online: https:/ / paidromania.ro/en/description (accessed on 31 August 2018).

61. Tapsell, S.; McCarthy, S.; Faulkner, H.; Alexander, M.; Social Vulnerability and Natural Hazards. CapHaz-Net WP4 Report. Available online: http:/ / caphaz-net.org/outcomes-results/CapHaz-Net_WP4_ Social-Vulnerability.pdf. (accessed on 17 June 2015).

(C) 2018 by the author. Licensee MDPI, Basel, Switzerland. This article is an open access article distributed under the terms and conditions of the Creative Commons Attribution (CC BY) license (http://creativecommons.org/licenses/by/4.0/). 